\title{
The impact of sieving on heterotrophic respiration response to water content in loamy and sandy topsoils
}

\author{
M. Herbst ${ }^{1}$, W. Tappe ${ }^{1}$, S. Kummer ${ }^{1}$ and H. Vereecken ${ }^{1}$ \\ [1] Agrosphere Institute, IBG-3, Forschungszentrum Jülich GmbH, Germany \\ Correspondence to: M. Herbst (m.herbst@ffz-juelich.de)
}

\begin{abstract}
Understanding the relation between soil heterotrophic respiration and water content is important for the prediction of climate change effects on soil $\mathrm{CO}_{2}$ emissions. In order to quantify the influence of air-drying and sieving with $2 \mathrm{~mm}$ meshes on the heterotrophic respiration response to soil water content we incubated intact cores and sieved samples of two loamy and two sandy soils for six levels of effective soil water saturation. We further determined soil textural properties and the soil water retention curves of the soils with the intent to identify links between soil physical characteristics and moisture sensitivity functions of heterotrophic respiration. The incubation of sieved and intact soils revealed distinct differences in the response of heterotrophic respiration to soil water content. The sieved soils exposed a threshold-type behaviour, whereas the undisturbed soils exposed a quadratic increase of heterotrophic respiration with increasing effective soil water saturation. Further, we detected significant correlations between the moisture response functions of the undisturbed soils and soil texture. From the comparison of sieved and intact soil incubations we conclude that the destruction of soil structure by sieving hampers the transferability of measured soil moisture response of heterotrophic respiration to real-world conditions. For modelling purposes we suggest the use of a quadratic function between relative respiration and effective saturation for soils with a clay fraction $<20 \%$.
\end{abstract}

keywords: carbon dioxide, disturbed vs. undisturbed, incubation, modelling, soil moisture, soil respiration 


\section{Introduction}

Soil respiration causes one of the largest terrestrial carbon fluxes and its accurate quantification is still a matter of on-going research (Reichstein and Beer, 2008; Wang et al., 2014). Heterotrophic soil respiration is produced by the degradation of soil organic material, which is known to depend on soil temperature and moisture. The impact of soil temperature on the carbon decomposition is pronounced (Davidson and Janssens, 2006; Exbrayat al., 2013). At a global perspective the second most relevant driver of heterotrophic respiration is soil water content (Bauer et al. 2008, Moyano et al., 2012). This becomes even more relevant against the background of global climate change (Falloon et al., 2011; Wang et al., 2014) since the predicted climate changes include altered precipitation regimes (IPCC, 2013). Dryer soils potentially counteract the effect of increased soil temperatures because a decrease in soil water content is generally expected to reduce soil heterotrophic respiration in terrestrial soils. Thus a precise mathematical description of the relation between soil water content and soil heterotrophic respiration is required (Blagodatsky and Smith, 2012).

In contrast to the temperature sensitivity function of respiration, for which basically only two types of functions, Arrhenius and $\mathrm{Q}_{10}$, are widely applied, there is a large diversity of functions used to model the soil water content influence on respiration (Falloon et al., 2011; Exbrayat et al., 2013). The effect of soil water content on heterotrophic respiration is manifold, however, there are two main influences: First, low water contents reduce the diffusion of nutrients toward microorganisms and microbial motility (Manzoni et al., 2014). Secondly, they may isolate the microbial habitats and thus inhibit microbial competition (Monga et al., 2008). Additional effects like e.g. water repellency (Lamparter et al., 2009), soil aeration (Schjonning et al., 1999; Ball et al., 2013), osmotic stress (Moyano et al., 2013), or substrate availability may also affect the soil water content response of heterotrophic respiration.

Even more striking, the soil moisture dependencies of respiration derived from field data (Davidson et al., 1998; Epron et al., 1999; Koizumi et al., 1999; Borken et al., 2003; Petersen et al., 2008; Wang et al., 2014) deviate from the functions derived from laboratory incubation experiments. One explanation for the consistent differences between field study and incubation derived functions may be the influence of other abiotic drivers. First of all, soil temperature obscures the intrinsic sensitivity of respiration towards soil water content under field conditions (Davidson et al., 1998; Borken et al., 2003). Further, diffusion limited 
transport of $\mathrm{CO}_{2}$ or oxygen deficits limiting the production of $\mathrm{CO}_{2}$ might also play a role under field conditions. Further complexity under field situations arises from the 'Birch effect' (Birch, 1958). Large peaks of respiration were observed due to precipitation pulses following extended drought periods, which could be explained by the rapid mineralization of dead microbial biomass and osmoregulatory compounds (Unger et al., 2010).

In contrast to field data, the soil water sensitivity function derived from incubation experiments tends to show a plateau or optimum-type behaviour. Various functions, like exponential, sinusoidal or Gaussian-type, are applied to describe this relation below this threshold (Moyano et al., 2013). A lot of process-based models apply this threshold-type approach (Bauer et al., 2008; Falloon et al., 2011; Exbrayat et al., 2013). The threshold-type function might partly result from the incubation procedure itself. The dependence of the accessibility of carbon to the decomposers on soil structure is documented in several studies (Six et al., 2000; Strong et al., 2004; Navarro-Garcia et al., 2012). During almost all of the incubation procedures documented in literature, the soil was sieved and homogenized (Manzoni et al., 2012; Moyano et al., 2012) prior to incubation, which clearly causes the destruction of the original soil structure. Lamparter et al. (2009) observed differences in the heterotrophic respiration response between disturbed and structural intact cores incubated at 3 soil water potentials and concluded that soil structure had a significant influence on respiration activity. Lomander et al., (1998) detected that respiration of disturbed soils was high, compared to field results, and stated that the transfer of results from the lab to field scale may be questionable. They expected an improvement by using intact soil cores for incubation experiments.

In order to estimate the parameters of the respiration response function to soil moisture, various soil properties such as porosity, texture, and bulk density were evaluated (Franzluebbers, 1999a; Thomsen et al., 1999). Moyano et al. (2012) established regression equations based on organic carbon content, clay content and bulk density to predict the normalized respiration response to moisture for a comprehensive data set on sieved soils. However, the predictive capability of soil hydraulic properties for the respiration response to moisture was not investigated in the abovementioned studies. As the soil water retention parameters largely depend on the pore structure, it might be expected that this also affects the response of carbon decomposition to various levels of soil water saturation.

The experiments presented in this study were intended to elucidate the following hypotheses: 
a) the heterotrophic respiration response function to soil moisture differs for disturbed and intact soils

b) the respiration response functions determined within this study for disturbed and intact soils can be validated with literature data on incubation and field experiments, respectively

c) the soil moisture sensitivity function of heterotrophic respiration is related to soil water retention parameters.

\section{Material and Methods}

In order to test these hypotheses we incubated sieved soil samples and intact soil cores at various soil water contents. We further determined basic soil properties and soil hydraulic parameters, which were subsequently related to parameters of the fitted moisture response functions.

Disturbed and intact soil samples of the plough horizon were taken at four agricultural fields in the lower Rhine embayment, Germany, at a depth of 5 to $10 \mathrm{~cm}$. The sites in Merzenhausen $\left(50^{\circ} 55^{\prime} 47^{\prime \prime} \mathrm{N}, 6^{\circ} 17^{\prime} 49^{\prime \prime}\right.$ E) and Selhausen $\left(50^{\circ} 52^{\prime} 9^{\prime \prime} \mathrm{N}, 6^{\circ} 27^{\prime} 0^{\prime \prime}\right.$ E) are characterized by Luvisols classified as silt loam, with the latter showing slightly higher amounts of sand (Table

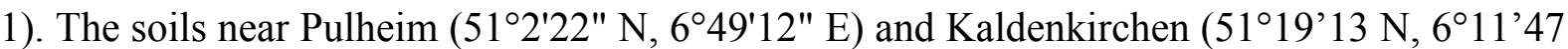

E) are classified as Cambisols with a sandy texture. The soils were sampled during spring, with the exception of the Pulheim soil, which was sampled during autumn, just before harvest. The four soils have a soil organic carbon (SOC) content varying at about $1 \%$ of mass, with a slightly lower SOC content for the sandy soils (Table 1). We further refer to the loamy soils of Selhausen and Merzenhausen as LS and LM, respectively. The sandy soils of Pulheim and Kaldenkirchen are referred to as SP and SK, respectively. A more detailed site description is given in the references listed in Table 1. At the sampling, the LM and LS soil had crumb structures and a moderate subangular blocky structure. Numerous earth worm burrows were detected for both loamy soils. For the SP and the SK soil only a crumb structure was recorded. The disturbed samples were air-dried and sieved with $2 \mathrm{~mm}$ meshes. 


\subsection{Soil hydraulic properties}

The soil water retention curves of the four undisturbed soils were experimentally determined following the standard soil physical procedures documented by Klute (1986) to obtain paired data points of pressure head and water content for the 5 replicates. The soil cores in Kopecki cylinders with a volume of $100 \mathrm{~cm}^{3}$ were equilibrated on a sand bed or on porous plates in high pressure cells. Gravimetric water content was determined by consecutive weighting and was converted to volumetric water content via bulk density.

The soil water retention data of the sieved soils was measured by a laboratory evaporation method. The HYPROP-device (UMS, Munich, Germany) was applied to measure soil water retention down to a pressure head of $\sim-900 \mathrm{~cm}$. For the very dry range, additional retention data was acquired using the WP4 dewpoint potentiameter (Decagon Devices, Pullman WA, USA) for pressure heads of $\sim-10^{4.2}, \sim-10^{5.4}$ and $\sim-10^{6.2} \mathrm{~cm}$.

Soil water retention data was fitted with the commonly applied approach according to Van Genuchten (1980):

$\Theta_{e}=\frac{\theta-\theta_{r}}{\theta_{s}-\theta_{r}}=\left[1+\left(\alpha_{1}|h|\right)^{n_{1}}\right]^{-m_{1}}$

where $\Theta_{\mathrm{e}}$ is the effective saturation, $\theta$ is the water content, $\theta_{\mathrm{s}}$ is the saturated water content, $\theta_{\mathrm{r}}$ is the residual water content, $\alpha_{1}$ is the inverse air entry pressure, $n_{l}$ is the slope parameter, $m_{1}$ is equal to $1-1 / n_{1}$ and $h$ is the pressure head. To account for the presence of multi-modal pore systems, observed for some of the undisturbed soils, Eq. 1 was extended by Durner (1994):

$\Theta_{e}=\sum_{i=1}^{k} \omega_{i}\left[\frac{1}{1+\left(\alpha_{i}|h|\right)^{n_{i}}}\right]^{-m_{i}}$

with $m_{i}=1-1 / n_{i}$, and the index $i$ looping over the number of pore systems In this study this approach was used to account for macroporous soils, resulting in a bimodal retention curve with $\omega_{2}=1-\omega_{1}$. In fitting Eqs. (1) and (2) to the data, $\theta_{\mathrm{r}}$ was fixed to a value of zero in case negative values of $\theta_{\mathrm{r}}$ would have been estimated. Effective saturation is defined as $\Theta_{\mathrm{e}}=\left(\theta-\theta_{\mathrm{r}}\right.$ 
)$/\left(\theta_{\mathrm{s}}-\theta_{\mathrm{r}}\right)$ and it is essentially identical to what in other studies is referred to as water-filled pore space WFPS (e.g. Franzluebbers et al., 1999a) or relative water saturation (e.g. Moyano et al., 2012).

\subsection{Model selection}

We investigated the effect of $\Theta_{\mathrm{e}}$ on basal respiration, as several studies showed that $\Theta_{\mathrm{e}}$ explains best the dependency of microbial activity (Paul et al., 2003, Moyano et al., 2012; Moyano et al., 2013) and it avoids hysteresis effects linked to pressure heads due to saturation or de-saturation of soil samples.

The model selection procedure was based on three criteria: The most relevant criterion was the corrected Akaike information criterion $\mathrm{AIC}_{\mathrm{c}}$ (Hurwich and Tsai, 1989), since it relates the model error to the number of model parameters $p$. The corrected $\mathrm{AIC}_{\mathrm{c}}$ was applied in this study because the original AIC (Akaike, 1974) is prone to overfitting for problems with a rather small number of observations $n$. In this study the maximum $n / p$ ratio of all tested models was 6. Smallest, i.e. more negative, $\mathrm{AIC}_{\mathrm{c}}$ values characterize the best model. The coefficient of model efficiency ME (Nash and Sutcliffe, 1970) is mathematically identical to the coefficient of determination. The ME relates the model error to the observed variance. Maximum ME is 1, indicating complete agreement between model and observations, whereas ME values between 0 and $-\infty$ point to inappropriate models, because the mean of the observations would be a better predictor. The root mean square error RMSE, as a standard measure of model error, has the unit of the investigated variable. The major criterion of model selection was the average $\mathrm{AIC}_{\mathrm{c}}$ over the four soils, but we rejected approaches in case a single soil showed a ME $<0.5$ and less than half of the variation in the data would have been explained by the model.

Three alternative models were each tested for the sieved and the undisturbed soils. For the undisturbed soils we tested a one-parameter linear model:

$R\left(\Theta_{e}\right)=a \Theta_{e}$

where $R$ is the respiration and $a$ is the linear slope. This implies that respiration equals zero at zero water content. Extending Eq. 3 with the intercept $b$ represents a more flexible 2parameter model: 


$$
R\left(\Theta_{e}\right)=b+\mathrm{c} \Theta_{e}
$$

where parameter $c$ is the linear slope. Since we observed a slight convex shape in the measurements of the undisturbed soils, a model with a quadratic term was tested as well:

$$
R\left(\Theta_{e}\right)=d+g \Theta_{\mathrm{e}}^{2}
$$

where $d$ is the y-axis intercept and $g$ is the quadratic slope parameter. This type of function was suggested by Lomander et al. (1998) to model the respiration response to soil moisture. For the sieved soils a Gaussian-type model was tested:

$R\left(\Theta_{e}\right)=j+k\left(1-e^{\left(-\left(\frac{\Theta_{e}}{t_{r}}\right)^{2}\right)}\right)$

where $j$ is the intercept, $k$ is a scaling parameter and $t_{r}$ represents the effective saturation where the concave shape of the function switches to a convex shape. We further tested a square root function:

$R\left(\Theta_{e}\right)=m+q \sqrt{\Theta_{e}}$

where $m$ is the y-axis intercept and $q$ scales the square root term. A simplified version of the Gaussian-type function was represented by an exponential approach:

$R\left(\Theta_{e}\right)=r+s\left(1-e^{\left(-\Theta_{e}\right)}\right)$

where $r$ is the intercept and $s$ is a scaling parameter of the exponential term. We further tested various functions, like e.g. a parabolic approach (e.g. Franzluebbers, 1999a), however we just report on the three most promising approaches for each, the sieved and the undisturbed soils, here. For parameter estimation we applied the nonlinear least-squares Marquardt-Levenberg algorithm implemented in GNUPLOT. The finally selected models were checked for the residues to identify potential systematic errors.

\subsection{Normalized moisture sensitivity of respiration}

Normalization of the respiration data is relevant, since it allows for the comparison of soils with various absolute heterotrophic respiration levels (Castellano et al., 2011; Manzoni et al., 2012; Moyano et al., 2012). Further it allows for a comparison between the results of this study and literature data. It is the only way to provide the transfer of core scale results to model studies at field scale or even larger scales as many soil carbon models are based on 
relative respiration, i.e. a dimensionless reduction factor of heterotrophic respiration (Davidson et al., 1998; Bauer et al., 2008; Falloon et al., 2011; Exbrayat et al., 2013; Wang et al., 2014). It is important to mention that the normalization only affects the data in the direction of the y-axis, it does not alter the general shape of the respiration vs. soil moisture function.

The quadratic approach (Eq. 5) and the Gaussian-type approach (Eq. 6) were finally identified as the most suitable functions for the undisturbed and the sieved soils, respectively. Both functions and the respective measurements were normalized by the maximum respiration defined as the sum of parameters $d$ and $g$ for the undisturbed soils, and parameters $h$ and $k$ for the sieved soils. This reflects the theoretical maximum respiration since we expressed the soil moisture status in terms of the effective saturation $\Theta_{\mathrm{e}}$, ranging between 0 and 1 . Assuming that the theoretical maximum respiration occurs at $\Theta_{\mathrm{e}}=1$ (Lomander et al., 1998; Curtin et al., 2012) also allows for a simplification of the functions. For the undisturbed soils the normalized respiration $R_{n}=R\left(\Theta_{\mathrm{e}}\right) / R\left(\Theta_{\mathrm{e}}=1\right)$ was thus expressed as:

$R_{n}\left(\Theta_{e}\right)=1-g_{n}+g_{n} \Theta_{\mathrm{e}}^{2}$

where $g_{n}$ represents the only model parameter. In case Eq. 5 was fitted to the non-normlized respiration data and $d$ and $g$ are known, $g_{n}$ can be calculated as $g /(d+g)$. The normalized respiration of the sieved soils was expressed as:

$R_{n}\left(\Theta_{e}\right)=1-k_{n}+k_{n}\left(1-e^{\left(-\left(\frac{\Theta e}{t_{r}}\right)^{2}\right)}\right)$

where the number of parameters is reduced to $2, k_{n}$ and $t_{r}$. Parameter $t_{r}$ is not affected by the normalization of respiration. If $j$ and $k$ are known from Eq. $6, k_{n}$ can be calculated as $k /(j+k)$. Equation 10 is a continuous function, however the threshold effective saturation $\Theta_{\mathrm{e}, \mathrm{t}}$ at which $99 \%$ of the maximum respiration is given was defined as:

$\Theta_{e, t}=t_{r} \sqrt{-\log _{n}(0.01)}$

\subsection{Sample processing and respiration measurements}

After sampling, the undisturbed cores were directly placed on a porous plate with a tension of $-5 \mathrm{~cm}$ to adjust the sample to the uppermost of the investigated soil water contents and the respiration measurements were conducted. Thereafter, the cores were adjusted to the next 
lower soil water content, directly followed by the respiration measurements. This was repeated stepwise until the six investigated soil water contents and the respective respiration measurements were completed.

The disturbed sample material was stored at $8^{\circ} \mathrm{C}$ until the soil was sieved to $2 \mathrm{~mm}$ and stored for another seven days at room temperature. In the next step, the sieved soils were wetted to the required soil water content. In order to minimize evaporation loss of water, directly after the adjustment of the soil water content the sieved soils were repacked into Kopecki cylinders and incubated. It is well known that drying and sieving will induce a flush of soil respiration after rewetting, which could have affected the soil moisture response of respiration for the disturbed soils. For this reason we established the conditioning period of 7 days after soil sieving at field moisture status. According to Franzluebbers (1999b) the carbon mineralisation of disturbed samples within the first 3 days of incubation (without conditioning period) is highly related to cumulative carbon mineralisation over 24 days, basal soil respiration and soil microbial biomass. Please note that in our study the samples were treated the same way prior to incubation for the 6 investigated levels of effective saturation, thus an effect of sample handling prior to the incubation is not likely to affect the functional relation between respiration and effective saturation of the undisturbed samples.

Both, disturbed and intact samples were incubated in the same type of steel cylinders and with identical soil masses. Control samples of the intact and the disturbed soils were kept at field moisture state and were monitored over the entire period of the experiment to verify that basal respiration did not decrease over time.

Respiration measurements were performed with an automated 12-channel respirometer (Biometric Systems, Weiterstadt, Germany) equipped with a zirconiumoxyd-sensor type FCX-MC-CH and two IR-sensors with a maximum detection range of $5000 \mathrm{ppm}$ and $5 \mathrm{ppm}$, respectively (Madur electronics; madirD01v3). The limit of quantification was $0.144 \mathrm{mg} \mathrm{CO}_{2}$ $\mathrm{d}^{-1}$ for the sensitive IR-sensor. Instead of commonly used glass bottles, in-house manufactured flow-through systems (180 mL volume) were applied to expose the soil samples. Disturbed soil samples with a volume of about $75 \mathrm{~cm}^{3}$ and the intact samples with a volume of about $50 \mathrm{~cm}^{3}$ were set in Kopecki cylinders on glass-frits within the flow-through cells allowing for an optimal gas exchange. Compared to the cores for the soil water retention measurements, half the volume was chosen for the incubation of the intact samples in order to minimize the effect of diffusion limitation (Curtin et al., 2012). The $\mathrm{CO}_{2}$ efflux was measured 
semi-continuously by switching the gas fluxes between the sensors and the respective samples by means of a multiplex valve. One measurement cycle covered the following procedures for each sample: refresh (6 times the gasphase-volume with ambient air at $300 \mathrm{~mL} \mathrm{~min}^{-1}$ analyzing $\left(2 \mathrm{~min}\right.$ at $\left.75 \mathrm{~mL} \mathrm{~min}^{-1}\right)$ - incubation $(75 \mathrm{~min})$ - analyzing - refresh. Each sample was incubated at $20^{\circ} \mathrm{C}$ for 5 days and the respective curves reflecting the $\mathrm{CO}_{2}$ release consisted of about 100 data points. A model was fitted to this $\mathrm{CO}_{2}$ release raw data to determine the respiration rate at the beginning of the incubation at $t=0$. Subsequently this respiration rate was averaged for the 5 replicates and related to the soil water content. Examples of raw data and details on the fit procedure are presented in the supplementary material.

It became a standard to use 5 replicates of $100 \mathrm{~cm}^{3}$ each for the determination of the smallscale variability of soil hydraulic properties. Within this study we also rely on 5 replicates for the incubation experiments, even though the sample volume of $50 \mathrm{~cm}^{3}$ was smaller in order to avoid diffusion limitation effects. The standard deviations of the replicates presented in the discussion section show that the variation of the respiration response for the intact and the disturbed samples is at similar magnitude.

\section{Results}

\subsection{Soil water retention curves}

Figure 1 shows the measured soil water retention data and the respective model fits according to Eqs. 1 and 2. The original Mualem/Van Genuchten approach (Eq. 1) did not fit the observed water content near saturation well for the undisturbed loamy soils due to the presence of a macroporous pore domain and is therefore not shown.

The saturated water content is lower for the sandy soils than for the loamy soils (see Table 2). This holds for the undisturbed soils as well as for the disturbed soils. As expected, also the decrease of water content with pressure head is steeper than determined for the loamy soils (Fig. 1a). The observed water contents of the undisturbed LM and LS soil near saturation were always higher than the fit suggested, which indicates the presence of macropores. Those are defined as pores with a diameter of $75 \mu \mathrm{m}$ or larger (Soil Science Glossary Terms Committee, 2008) and they are only water filled at small negative pressure heads. Macropores are typically found in clayey to loamy soils (Durner, 1994). Extending Eq. 1 with Eq. 2 
allowed an improved fit and the determination of the parameters for two pore systems (Table 2). In the following the estimated water content at saturation was used to normalize the measured soil water content to effective saturation.

Comparing the retention curves of the sieved and the undisturbed soils reveals the biggest difference in water content at saturation $\theta_{\mathrm{s}}$. The sieving and repacking increased $\theta_{\mathrm{s}}$ by a value between 0.07 and $0.14 \mathrm{~cm}^{3} \mathrm{~cm}^{-3}$. This could mainly be explained by the lower bulk densities of the sieved soils of 1.16, 0.93, 1.10 and $1.26 \mathrm{~g} \mathrm{~cm}^{-3}$ for the LM, LS, SP and SK soil, respectively. The undisturbed soils showed bulk densities ranging between 1.36 and $1.46 \mathrm{~g}$ $\mathrm{cm}^{-3}$ (Table 1). Analogous to the undisturbed soils, the sieved soils show higher values of $\theta_{\mathrm{s}}$ for the loamy soils. Another striking feature of the sieving is the loss of macropores detected for the undisturbed loamy soils. The sieving homogenized the pore structure of the loamy soils. Soil hydraulic parameters $\alpha_{1}$ and $n_{l}$ changed moderately. The biggest change was here observed for the $n_{1}$ parameter of the SK soil, which increased to a value of 1.77 , typically causing the rapid decrease of water contents at pressure heads slightly lower than the air entry pressure of sandy soils.

\subsection{Model selection}

The sieved soils were tested for fits with the Gaussian-type model (Eq. 6), the square root model (Eq. 7), and the exponential model (Eq. 8). Compared to the Gaussian-type approach, the square root model and the exponential model provide slightly lower average $\mathrm{AIC}_{\mathrm{c}}$ values. This mainly results from the fact that the latter are based on 2 parameters, whereas the Gaussian-type model applies 3 parameters. However, both 2-parameter approaches fail to simulate the behaviour of the SK soil, indicated by ME values of 0.48 and 0.46 and higher RMSEs. For this reason the Gaussian-type model was chosen to simulate the behaviour of the sieved soils.

The linear model of Eq. 4 provided a good fit for the undisturbed soils in terms of $\mathrm{AIC}_{\mathrm{c}}, \mathrm{ME}$ and RMSE (see Table 3). However, the t-values of the LS and LM soils indicated that the intercept was not significantly different from zero. Further, the SP soil had an intercept different from zero at low significance. Thus, a linear model without intercept (Eq. 3) was tested. This simplified linear model showed larger errors in terms of ME and RMSE, particularly for the sandy soils. Likewise, the average $\mathrm{AIC}_{\mathrm{c}}$ of the four soils was not smaller, 
compared to the linear model with intercept, despite the fact that the simplified linear model had only one parameter. At this point the linear model without intercept was ruled out. The 2parameter quadratic model (Eq. 5) provided slightly lower average ME and a slightly higher average RMSE than the linear model with intercept. However, the quadratic model had the overall lowest average $\mathrm{AIC}_{\mathrm{c}}$ and was thus finally chosen as the most appropriate model to fit the undisturbed soils.

Further, a cross-comparison was carried out by fitting the finally selected model of the undisturbed soils to the sieved soils and vice versa (Table 3). Applying the Gaussian-type model to the undisturbed soils provides slightly improved ME and RMSE, simply as a result of an additional model parameter. However, the average $\mathrm{AIC}_{\mathrm{c}}$ is higher than for the quadratic 2-parameter model pointing to the quadratic model to be more appropriate. Moreover, the overall convex shape of the Gaussian-type functions fitted to the sieved soils turns into a concave shape for the undisturbed soils and also provide erroneous model parameters. Except for the SP soil this was particularly observed for the parameter $t_{r}$ with values clearly larger than 1 . The fits of the quadratic model to the sieved soils in turn provide a slightly improved average $\mathrm{AIC}_{\mathrm{c}}$. Again, this is a result of the smaller number of parameters. On the other hand this also leads to a very low ME of 0.31 for the SK soil, which alone would cause a rejection of the quadratic model for the sieved soils. Further, a clearly lower average ME and an average RMSE being twice as high as observed for Gaussian-type model was detected.

\subsection{Respiration response of sieved vs. intact soils}

The measurements of respiration against effective saturation for the sieved soils expose a plateau-type behaviour (Fig. 2). With increasing effective pore water saturation the basal respiration increases up to a certain threshold. Above this water saturation threshold the respiration remains at an almost constant level. This is prominent for the SK soil, reaching the turning point $t_{r}$ at an effective saturation of about 0.09 (Table 4). In contrast, the SP, LS and LM soils reach the turning point at saturation values of $0.42,0.38$ and 0.46 , respectively. The highest levels of basal respiration of $\sim 0.012 \mu \mathrm{g} \mathrm{CO}_{2} \mathrm{~min}^{-1} \mathrm{~g}$ soil ${ }^{-1}$ were measured for the two sandy soils at levels of effective saturation between 0.6 and 0.8. Both loamy soils reveal lower maximum basal respirations varying around $0.008 \mu \mathrm{g} \mathrm{CO} \mathrm{min}^{-1} \mathrm{~g} \mathrm{soil}^{-1}$.

To account for this plateau-type behaviour the Gaussian-type Eq. 6 was fitted to the measurements (see Fig. 2). The ME varied between 0.88 and 0.98 and the root mean square 
error RMSE varied between 0.00059 and $0.00071 \mu \mathrm{g} \mathrm{CO}_{2} \min ^{-1} \mathrm{~g}$ soil ${ }^{-1}$ (Table 3), which points to acceptable model fits for the four soils. The model for the SK soil reveals a rather sharp increase in respiration with increasing effective saturation, whereas the other sandy soil model (SP) rather behaves similar to the two loamy soils, showing moderate slopes (see parameter $k$, Table 4). The estimated threshold saturation $\Theta_{\mathrm{e}, \mathrm{t}}$ of the SK model was very low, at $19 \%$ of saturation. The $\Theta_{\mathrm{e}, \mathrm{t}}$ of the other soils was much closer to saturation at values of 81 , 99 and $89 \%$ for LS, LM and SP, respectively.

The measurements of respiration vs. effective saturation for the undisturbed soils did not show a plateau-type behaviour as it was observed for the sieved soils (Fig. 3), but it rather showed an increase of respiration over the observed range of effective saturation. But there is one exception: The measurements of the SP soil point to a smaller increase of respiration at high effective saturation. Compared to the other soils, the SP soil also showed a much higher overall level of respiration activity.

We fitted Eq. 5 to the measurements of the undisturbed soils. Table 4 summarizes the parameters and the goodness of fit criteria for each of the quadratic models are given in Table 3. The RMSE as well as the ME proved good model fits. The ME of 0.72 for the SP soil was lower, but still indicated an acceptable model.

To allow for comparison with literature data and to provide improved comparability between the investigated soils, the respiration data was normalized. We used the maximum respiration projected by the respective model functions for an effective saturation of 1 to normalize data. Figure 4 shows the normalized respiration and the respective models of the sieved soils together with literature data of Lee et al. (2004). They incubated mineral soil samples of a Hollis series spodosol at various soil water contents. Soil water content was converted to effective saturation assuming that the highest applied soil water content was close to $\theta_{\mathrm{s}}$, which was eventually set to $0.56 \mathrm{~cm}^{3} \mathrm{~cm}^{-3}$. Figure 4 shows that the data of Lee et al. (2004) was fitted reasonably well by Eq. 10 . The resulting estimated effective saturation threshold $\theta_{\mathrm{t}}$ was 0.29. According to Lee et al. (2004), soil texture was a 'stony sandy loam or loamy sand'. The measurements carried out within this study for the SK soil, classified as sand, are close to the normalized respiration data determined by Lee et al. (2004). The normalized respiration response to effective saturation does not group well according to soil texture for the sieved soils. The loamy soils are quite close to each other, however the sandy soils represent the 
extremes. The SK soil approaches the plateau at low saturation, whereas the SP soil has the highest $\theta_{\mathrm{t}}$ of the soils investigated.

The normalized data of the undisturbed samples is depicted in Fig. 5. After normalization, the two loamy and the two sandy soils group well. Compared to the sieved soils, the differences between the undisturbed soils are clearly smaller after normalization. For comparison with our data we included the field measurements of Borken et al. (2003) and the incubation experiments with intact cores performed by Petersen et al. (2008). The literature data was handled analogous to the data of this study. A fit of Eq. 5 provided the theoretical respiration at maximum effective saturation, which was subsequently used to normalize respiration data. The field respiration data by Borken et al. (2003) were actually residuals after the elimination of soil temperature effects, which probably explains some of the scatter in the data. The measured soil water contents of that study were converted to effective saturation assuming a $\theta_{\mathrm{s}}$ of $0.35 \mathrm{~cm}^{3} \mathrm{~cm}^{-3}$. The soil water content determined by Petersen et al. (2008) was converted to $\Theta_{\mathrm{e}}$ assuming a $\theta_{\mathrm{s}}$ of $0.494 \mathrm{~cm}^{3} \mathrm{~cm}^{-3}$, again based on the assumption that the highest measured water contents were close to saturation. Also the A horizon field data of Borken et al. (2003) and the intact cores of the fine sandy Dronninglund top soil $(14-18 \mathrm{~cm}$, shallow tillage treatment) incubated by Petersen et al. (2008) are well approximated by the quadratic model. Equation 9 fitted to the fine sandy Dronninglund soil had a slope parameter $g_{n}$ of 0.67 , which compares nicely to the $g_{n}$ values of 0.63 and 0.65 determined for the sandy SP and SK soil, respectively. Higher $g_{n}$ values of 0.77 and 0.74 were detected for the loamy LM and LS soil, respectively. This again compares well to the $g_{n}$ value of 0.81 determined for the sandy loam A-Horizon investigated by Borken et al. (2003).

\subsection{Correlation between soil properties and moisture sensitivity parameters}

Pearson correlation coefficients were computed in order to detect dependencies between the normalized respiration/soil moisture function parameters (Tab. 4), soil properties (Tab. 1), and soil hydraulic parameters (Tab. 2). Clay, silt, sand, and organic carbon content as well as mean grain size diameter were correlated to the normalized moisture response function parameters of both, the sieved and the undisturbed soils. Bulk densitiy and hydraulic properties of the undisturbed soils were correlated to the slope parameter $g_{n}$ of the normalized moisture response function of the undisturbed soils only. For the sieved soils this was handled analogous. Strong $(|r|>0.96)$ and significant correlations at $97.5 \%$ probability level were 
detected between the soil retention function slope parameter $n_{l}$ and the slope parameter $k_{n}$ and the threshold parameter $t_{r}$ of the sieved soils (Table 5). For the undisturbed soils, strong correlations at $99 \%$ probability level were found between slope parameter $g_{n}$ and the grain size fractions clay, silt and sand. Further, strong correlations at moderate significance were detected between slope parameter $g_{n}$ and bulk density and between $g_{n}$ and the inverse of the air entry pressure $\alpha_{1}$.

\section{Discussion}

\subsection{Soil hydraulic characteristics}

The soil water retention curves determined for the two loamy and the two sandy undisturbed soils are in the range reported in literature (e.g. van Genuchten, 1980; Durner, 1994). The typical characteristics of sandy soils having a sharp decrease of water content with pressure head, indicated by a rather large value of the $\mathrm{n}_{1}$ parameter, and low air entry pressures, indicated by a large $\alpha_{1}$, was observed for the SP and SK soils (Table 2). The distinct macroporosity detected for the LM and LS soil is also typical for loamy soils. Macropores are mainly attributed to the generation of soil aggregates and biological soil forming processes (Durner, 1994) and the stability of the macropore system largely depends on the clay content and on the amount of SOC (Bronick and Lal, 2005). The loamy and the sandy soils investigated in this study are at similar SOC levels. Thus, the difference in soil structure in terms of macroporosity should be explained by the higher clay content of the loamy soils (Table 1). Compared to the sandy soils, the aggregate formation detected for the LM and LS soils also points to the usually marked soil structure of loamy soils despite any mechanical perturbation occurring in agricultural top soils (Bronick and Lal, 2005).

Mechanical soil disturbance clearly alters the soil water retention characteristics. The two main features of disturbed soils are the absence of macropores and an increase in porosity (Fig. 1). Further, disturbed soils are expected to have a less continuous and more tortuous pore system than intact samples (Schjonning et al., 1999). As a consequence, volumetric water contents measured in the lab for disturbed soils cover a different range of water-filled pore sizes than the same volumetric water contents measured for the intact field soil. The strength of this effect largely depends on the degree of soil aggregation and macroporosity of the intact soil, as well as on the bulk density established for the re-packed soils. The latter 
alone generates a measurable effect on the respiration response to soil water content (Franzluebbers, 1999a).

\subsection{Respiration response of sieved vs. intact soils}

The soil moisture response of heterotrophic respiration has been measured on the same soil material using a consistent approach allowing for a direct comparison. One of the major findings of this study is that the incubation of sieved and intact soils revealed distinct differences in the sensitivity of soil basal respiration to soil water content. The sieved soils show on average a threshold type behaviour characterized by an insensitivity of respiration above a certain effective saturation (Fig. 4). In contrast, the undisturbed soils expose a sensitivity of respiration over the entire range of effective saturation (Fig. 5). Both characteristics are documented in literature. The plateau-type behaviour of sieved soils was observed in many studies (e.g. Doran et al., 1990; Howard and Howard, 1993; Gulledge and Schimel, 1998; Franzluebbers, 1999a; Rey et al., 2005; Miller et al., 2005). However, some of the above-mentioned studies (Doran et al., 1990; Franzluebbers, 1999a; Rey et al., 2005) also report a decrease of heterotrophic respiration above a certain maximum soil moisture, attributed to the effect of an oxygen deficit near saturation (Falloon et al., 2011). In our incubation experiments with sieved soils such an effect was not observed. This might be explained by the fact that we did not adjust the samples to effective saturations above $80 \%$, which was originally done to prevent diffusion limitations to the $\mathrm{CO}_{2}$ emission. Further, the experimental setup might play a role. In our respirometer approach the repeated flushing of flow-trough cells might have improved soil aeration, in contrast to classic incubation experiments with $\mathrm{CO}_{2}$ traps. On the other hand, Højberg et al. (1994) reported that oxygen diffused 2-4 $\mathrm{mm}$ into water-saturated aggregates, which could also explain the lack of an oxygen deficit for the microbial activity near saturation under experimental conditions. In any case, splitting this into two separate processes, water availability and oxygen deficit, appears to be meaningful (e.g. Simunek and Suarez, 1993).

The contrasting behaviour of undisturbed soils is also documented in literature, even though incubation experiments with intact soils are rare (Manzoni et al., 2012). Studies on undisturbed soils were carried out by Peterson et al. (2008) and Muhr et al. (2010). The latter, however, related respiration sensitivity to soil water pressure head only, not to gravimetric or volumetric water content, which precludes any comparison to our findings. The data 
published by Petersen et al., (2008) was actually used in this study for comparison with our data (Fig. 5) and is well in line with our findings. Petersen et al. (2008) investigated field data of two agricultural sites at two soil depths and for two management treatments and the vast majority of the data exposed a continuous increase of heterotrophic respiration over the observed range of soil water content. Curtin et al. (2012) measured the carbon mineralized (i.e. the $\mathrm{CO}_{2}-\mathrm{C}$ produced) at various relative water contents and determined linear functions between $\mathrm{C}$ mineralization and water content. However, their soils were sieved with $6 \mathrm{~mm}$ meshes, which probably did not destroy the aggregate size (i.e. pore size) relevant for undisturbed carbon/soil water interaction. Franzluebbers (1999b) investigated the effect of the extent of sieving on the respiration response and detected that the mesh size used for sieving influenced the soil moisture/respiration relationship in a predictable manner.

Field studies on the respiration vs. water content relation on the other hand are linked with the inherent issue that, apart from soil water content, also the varying soil temperature significantly influences heterotrophic respiration activity. The confounding effects of soil temperature and water content could even lead to negative slopes for the relation between soil respiration and soil water content (Davidson et al., 1998; Koizumi et al., 1999). One appropriate way to handle the confounding effect of temperature and moisture is to limit the temperature range the respiration/water content function is established for. For example Epron et al. (1999) restricted the observations of soil temperature to data within a $4^{\circ}$ range and observed a linear increase of soil $\mathrm{CO}_{2}$ efflux with increasing volumetric water content. Another option to separate the confounding factors is the elimination of the temperature sensitivity, based on the Arrhenius equation, prior to the examination of the respiration/water content function. This was suggested by Borken et al. (2003) and the residuals were well approximated by the quadratic approach presented as Eq. 9 (see Fig. 5).

Fig. 6 shows the normalized respiration data of all sieved and all undisturbed soils and respective model fits. For the undisturbed soils, parameter $g_{n}$ was 0.694 with an asymptotic standard error of $\pm 3.1 \%$. The fit RMSE was 0.078 , which is acceptable against the range of normalized respiration between 0.2 and 1.0. Figure 5 already showed that the difference between the model fit for the sandy and for the loamy soils is rather small. On average, the biggest differences between the response of sieved and undisturbed soils occurred at the midrange effective saturation, approximately between 0.3 and 0.8 with a maximum divergence at about 0.5 . Outside this range, in the very dry and in the very wet range, the response curves 
converge. Lamparter et al. (2009) detected higher absolute respiration of aggregated soils compared to homogenized soils at pressure heads of $-10^{1.8} \mathrm{~cm}$. The opposite was found for aggregated soils at $-10^{2.5} \mathrm{~cm}$, and at $-10^{3.2} \mathrm{~cm}$ no difference was found. This corroborates the findings of our study in the sense that sieved and disturbed soils show little differences in their respiration response to moisture at the very dry range $\left(-10^{3.2} \mathrm{~cm}\right)$. At the medium range effective saturation, pressure heads of $-10^{2.5}$ and $-10^{1.8} \mathrm{~cm}$, however the respiration responses to moisture diverge.

At this point a detailed explanation for the difference in the behaviour of sieved and undisturbed samples is not straightforward and it surely is subject to future research. The soil disturbance by drying and sieving has a two-sided effect. On one hand the pore structure is massively affected, which in turn affects the pore sizes filled with water at a specific volumetric water content, i.e. the soil water retention, (Fig. 1). On the other hand, carbon is released due to the destruction of soil aggregates (Navarro-Garcia et al., 2012) and substrate becomes available at pore sizes that provided less carbon for decomposition prior to soil disturbance (Strong et al., 2004). Both effects add up and cause the differences of soil respiration response to water content of sieved and undisturbed soils. For the undisturbed soils, the arrangement of carbon substrate, organisms and water in the pore system was selforganized in such a way that soil microbial respiration decreased immediately as water-filled pore space was lost. The fact that the disturbed samples behave differently probably indicates that the location of a certain carbon quality in a pore fraction plays a significant role. Organic matter located in smaller pores is more protected against decomposition than that located in larger pores (Strong et al., 2004). Mechanic disruption exposes the formerly protected carbon and the availability of carbon at pores of medium to large diameter increases, which explains the higher relative respiration rates of the disturbed soils compared to the intact soils for medium range effective saturation as discussed above and shown in Fig. 6. This finding is also in line with the concept of soil structure in terms of macro- and microaggregates having a significant influence on the turnover of soil carbon (Six et al., 2000; Malamoud et al., 2009; Moyano et al., 2013). According to Masse et al. (2007), mineral and organic particles form differently sized aggregates and this organization generates microenvironments with varying degrees of microbial activity. Also the gas diffusion rates within and between aggregates drive microbial respiration (Ball et al., 2013). Moldrup et al. (2001) detected a difference of one order of magnitude for the air permeability of sieved vs. undisturbed soils. All these 
processes are altered when the original soil physical structure is destructed prior to incubation, leading to significant differences in the respiration/soil water content functional behaviour.

Compared to the other undisturbed soils, the SP soil did not show a clear quadratic increase in respiration (Fig. 3), also indicated by a slightly lower ME of 0.72 (Table 3). Further, the absolute level of respiration is higher than for the other three undisturbed soils. For all of the sieved soils, the absolute levels of respiration are quite similar (Fig. 2), which again points to a severe effect of the sieving on the availability of carbon at a given effective water saturation.

This study was conducted with the intention to foster the application of soil moisture sensitivity functions of heterotrophic respiration for modelling purposes from local to large scale. The comparison of seven soil moisture sensitivity functions implemented in commonly applied carbon turnover models (Bauer et al., 2008) showed an insensitivity of respiration at effective saturations larger than about 50\%. Due to the application of threshold-type functions the soil moisture in the upper range does not cause any increase in relative respiration. The findings of our study however suggest that this sensitivity does exist and this would also affect the modelling of carbon balances and the feedback to climate change in terms of the precipitation regime. This holds particularly for temperate and humid ecosystems characterized by extensive periods of soil moisture in the medium to wet range. We suggest the application of the quadratic approach (Eq. 9) to model the response of relative respiration to soil moisture. For sandy soils parameter $g_{n}$ should be set to 0.643 , whereas a value of 0.756 should be appropriate for loamy soils. For both textures, the single measurements do not deviate much from the average parameters given above (see Table 4 and Fig. 5). At this point the application of the quadratic model approach is clearly limited to loamy or sandy soils. We did not investigate clay soils ( $>20 \%$ clay) and there is indication that the soil moisture response of clay soils might differ from what we detected for loamy and sandy soils. Manzoni et al. (2014) demonstrated that the solute diffusivity as a function of volumetric soil moisture was very similar for loamy and sandy soils, but differed significantly for clay.

\subsection{Correlation between soil properties and moisture sensitivity parameters}

Generally, correlations based on observations of four soils only have to be interpreted carefully. Our results for the sieved soils indicate statistically significant correlations between the soil moisture response function parameters $k_{n}$ and $t_{r}$ and the soil hydraulic parameter $n_{l}$, 
but no other soil property showed a correlation to $k_{n}$ or $t_{r}$. Moyano et al. (2012) detected an increase in optimal moisture for respiration with increasing clay fraction. In our study also a moderate positive but non-significant correlation was found for $t_{r}$ and clay content of the sieved soils.

For the undisturbed soils, parameter $g_{n}$ groups nicely into loamy and sandy soils, and high correlations were detected between the soil textural fractions and $g_{n}$. Also bulk density and soil hydraulic parameter $\alpha_{1}$ show high correlations with $g_{n}$. Apparently, the significant correlation to just one hydraulic parameter does not justify the effort required for the determination of the soil water retention characteristic. The easier measurable soil textural data should enable the prediction of the moisture response function parameter $g_{n}$. A multiple regression approach, using clay and silt content and maybe bulk density as well, could provide enough information for a sound estimate of the respiration response function to soil moisture. Of course more research on this topic, based on a larger number and variety of undisturbed soils, is required.

There is a shift in the correlations to soil properties of the sieved soils and the undisturbed soils. The sieved soils just show few correlations to soil properties, only one hydraulic parameter shows a strong and significant correlation, whereas the undisturbed soils show five significant and strong correlations without any overlap to the correlation of the sieved soils. This again points to a difference in the soil respiration response to moisture of the sieved and the undisturbed soils.

\section{Conclusions}

From the comparison of sieved and intact soil incubations we conclude that soil structure plays an important role for the moisture response function of heterotrophic respiration. Sieving of soils introduced scatter in the moisture response functions not apparent in undisturbed soils with intact structure. Moreover, the sieving affected the functional relation between effective soil water saturation and heterotrophic respiration. Both findings indicate that the destruction of soil structure significantly hampers the transferability of moisture response functions based on incubation of disturbed soil samples to field conditions.

For modelling purposes we recommend the quadratic function between relative respiration and effective saturation for undisturbed soils with a clay fraction lower than $20 \%$. Our results 
indicate that the slope parameter of the quadratic approach could be estimated from soil texture, bulk density and SOC content.

\section{Acknowledgements}

This research was supported by TERENO (Terrestrial Environmental Observatories) of the Helmholtz Gemeinschaft. We gratefully acknowledge Anke Langen for the support in the soil physics lab. 


\section{References}

Akaike, H., 1974. New look at statistical-model identification. IEEE Trans. Autom. Control AC19(6), 716-723.

Ball, B.C., 2013. Soil structure and greenhouse gas emissions: a synthesis of 20 years of experimentation. Europ. J. Soil Sci. 64, 357-373.

Bauer, J., Herbst, M., Huisman, J.A., Weihermüller, L., Vereecken, H., 2008. Sensitivity of simulated soil heterotrophic respiration to temperature and moisture reduction functions. Geoderma 145, 17-27. doi: 10.1016/j.geoderma.2008.01.026

Birch, H.F., 1958. The effect of soil drying on humus decomposition and nitrogen availability. Plant and Soil 10, 9-31.

Blagodatsky, S., Smith, P., 2012. Soil physics meets soil biology: Towards better mechanistic prediction of greenhouse gas emissions from soil. Soil Biology \& Biochemistry 47, 7892.

Borken, W., Davidson, E.A., Savage, K., Gaudinski, J., Trumbore, S.E., 2003. Drying and wetting effects on carbon dioxide release from organic horizons. Soil Sci. Soc. Am. J. 67, 1888-1896.

Bronick, C.J., Lal, R., 2005. Soil structure and management: a review. Geoderma 124, 3-22.

Castellano, M.J., Schmidt, J.P., Kaye, J.P., Walker, C., Graham, C.B., Lin, H., Dell, C., 2011. Hydrological controls on heterotrophic soil respiration across an agricultural landscape. Geoderma 162, 273-280.

Curtin, D., Beare, M.H., Hernandez-Ramirez, G., 2012. Temperature and moisture effects on microbial biomass and soil organic matter mineralization. Soil Sci. Soc. Am. J. 76, 2055-2067.

Davidson, E.A., Belk, E., Boone, R.D., 1998. Soil water content and temperature as independent or confounded factors controlling soil respiration in a temperate mixed hardwood forest. Global Change Biology 4, 217-227.

Davidson, E.A., Janssens, I.A., 2006. Temperature sensitivity of soil carbon decomposition and feedbacks to climate change. Nature 440, 165-173. 
Doran, J.W., Mielke, L.N., Power, J.F., 1990. Microbial activity as regulated by soil waterfilled pore space. Transactions $14^{\text {th }}$ International Congress of Soil Science. Symposium III-3; Ecology of soil microorganisms in the microhabitat environments III, 94-99. August 12-18, 1990; Kyoto, Japan.

Durner, W., 1994. Hydraulic conductivity estimation for soils with heterogeneous pore structure. Water Resources Research 30, 211-223.

Epron, D., Farque, L., Lucot, E., Badot, P.-M., 1999. Soil $\mathrm{CO}_{2}$ efflux in a beech forest: dependence on soil temperature and soil water content. Ann. For. Sci. 56, 221-226.

Exbrayat, J.F., Pitman, A.J., Abramowitz, G., Wang, Y.P., 2013. Sensitivity of net ecosystem exchange and heterotrophic respiration to parameterization uncertainty. Journal of Geophysical Research: Atmospheres 118, 1640-1651.

Falloon, P., Jones, C.D., Ades, M., Paul, K., 2011. Direct soil moisture controls of future global carbon changes: An important source of uncertainty. Global Biogeochemical Cycles 25, GB3010. doi: 10.1029/21010GB003938.

Franzluebbers, A.J., 1999a. Microbial activity in response to water-filled pore space of variably eroded Piedmont soils. Applied Soil Ecology 11, 91-101.

Franzluebbers, A.J., 1999b. Potential C and N mineralization and microbial biomass from intact and increasingly disturbed soils of varying texture. Soil Biol. Biochem. 31, 10831090.

Gulledge, J., Schimel, J.P., 1998. Moisture control over atmospheric $\mathrm{CH}_{4}$ consumption and $\mathrm{CO}_{2}$ production in diverse Alaskan soils. Soil Biol. Biochem. 30, 1127-1132.

Herbst, M., Prolingheuer, N., Graf, A., Huisman, J.A., Weihermüller, L., Vanderborght, J., 2009. Characterisation and understanding of bare soil respiration spatial variability at plot scale. Vadose Zone Journal 8, 762-771.

Højberg, O., Revsbech, N.P., Tiedje, J.M., 1994. Denitrification in soil aggregates analysed with microsensors for nitrous oxide and oxygen. Soil Sci. Soc. Am. J. 58, 1691-1698.

Howard, D.M., Howard, P.J.A., 1993. Relationships between $\mathrm{CO}_{2}$ evolution, moisture content and temperature for a range of soil types. Soil Biol. Biochem. 25, 1537-1546.

Hurvich, C.M., Tsai, C.L., 1989. Regression and time-series model selection in small samples. Biometrika 76, 297-307. 
IPCC, 2013. Summary for Policymakers. In: Climate Change 2013: The Physical Science Basis. Contribution of Working Group I to the Fifth Assessment Report of the Intergovernmental Panel on Climate Change. (Eds. Stocker, T.F., Qin, D., Plattner, G.K., Tignor, M., Allen, S.K., Boschung, J., Nauels, A., Yia, Y., Bex, V., Midgley, P.M.). pp. 4-20. Cambridge University Press. Cambridge, UK and New York, NY, USA.

Kasteel, R., Pütz, T., Vereecken, H., 2007. An experimental and numerical study on flow and transport in a field soil using zero-tension lysimeters and suction plates. European Journal of Soil Science 58, 632-645.

Klute, A., 1986. Water retention: laboratory methods. In: Campbell, G.S., Nielsen, D.R., Jackson, R.D., Klute, A., Mortland, M.M. (Eds.), Methods of soil analysis, Part 1 Physical and mineralogical Methods, $2^{\text {nd }}$ Ed., SSSA Book Series No 5, Soil Science Society of America, Madison, Wisconsin, USA, pp. 635-660.

Koizumi, H., Kontturi, M., Mariko, S., Nakadai, T., Bekko, Y., Mela, T., 1999. Soil respiration in three soil types in agricultural ecosystems in Finland. Acta Agric. Scand. Sect. B, Soil and Plant Sci. 49, 65-74.

Lamparter, A., Bachmann, J., Goebel, M.-O., Woche, S.K., 2009. Carbon mineralization in soil: Impact of wetting-drying, aggregation and water repellency. Geoderma 150, 324333.

Lee, X., Wu, H.-J., Sigler, J., Oishi C., Siccama, T., 2004. Rapid and transient response of soil respiration to rain. Global Change Biology 10, 1017-1026.

Lomander, A., Kätterer, T., Andren, O., 1998. Modelling the effects of temperature and soil moisture on $\mathrm{CO}_{2}$ evolution from top- and subsoil using a multi-compartment approach. Soil Biol. Biochem. 30, 2023-2030.

Malamoud, K., McBratney, A.B., Minasny, B., Field, D.J., 2009. Modelling how carbon affects soil structure. Geoderma 149, 19-26.

Manzoni, S., Schimel, J.P, Porporato, A., 2012. Responses of soil microbial communities to water stress: results from a meta analysis. Ecology 93, 930-938.

Manzoni, S., Schaeffer, S.M., Katul, G., Porporato, A., Schimel, J.P., 2014. A theoretical analysis of microbial eco-physiological and diffusion limitations to carbon cycling in drying soils. Soil Biol. Biochem. 73, 69-83. 
Masse, D., Cambier, C., Braumann, A., Sall, S., Assigbetse, K., Chotte, J.-L., 2007. MIOR: an individual-based model for simulating the spatial patterns of soil organic matter microbial decomposition. Europ. J. Soil Sci. 58, 1127-1135.

Miller, A.E., Schimel, J.P., Meixner, T. Sickman, J.O., Melack, J.M., 2005. Episodic rewetting enhances carbon and nitrogen release from chaparral soil. Soil Biol. Biochem. 37, 2195-2204.

Moldrup, P., Olesen, T., Komatsu, T., Schjonning, P., Rolston, D.E., 2001. Tortuosity, diffusivity, and permeability in the soil liquid and gaseous phases. Soil Sci. Soc. Am. J. 65:613-623.

Monga, O., Bousso, M., Garnier, P., Pot, V., 2008. 3D geometric structures and biological activity: Application to microbial soil organic matter decomposition in pore space. Ecological Modelling 216, 291-302.

Moyano F.E., Vasilyeva, N., Bouckaert, L., Cook, F., Craine, J., Curiel Yuste, J., Don, A., Epron, D., Formanek, P., Franzluebbers, A., Ilstedt, U., Kätterer, T., Orchard, V., Reichstein, M., Rey, A., Ruamps, L., Subke, J.-A., Thomsen, I.K., Chenu, C., 2012. The moisture response of soil heterotrophic respiration: interaction with soil properties. Biogeosciences 9, 1173-1182.

Moyano F.E., Manzoni, S, Chenu, C., 2013. Responses of soil heterotrophic respiration to moisture availability: An exploration of processes and models. Soil Biology \& Biochemistry 59, 72-85.

Muhr, J., Franke, J., Borken, W., 2010. Drying-rewetting events reduce C and N losses from a Norway spruce forest floor. Soil Biol. Biochem. 42, 1303-1312.

Nash, J.E., Sutcliffe, J.V., 1970. River flow forecasting through conceptual models part I - a discussion of principles. Journal of Hydrology 10, 282-290.

Navarro-Garcia, F., Casermeiro, M.A., Schimel, J.P., 2012. When structure means conservation: Effect of aggregate structure in controlling microbial responses to rewetting events. Soil Biology \& Biochemistry 44, 1-8.

Paul, K.I., Polglase, P.J., O’Connell, A.M., Carlyle, J.C., Smethurst, P.J., Khanna, P.K., 2003. Defining the relation between soil water content and net nitrogen mineralization. Europ. J. Soil Sci. 54, 39-47. 
Petersen, S., Schjonning, P., Thomsen, I.K., Christensen, B.T., 2008. Nitrous oxide evolution from structurally intact soil as influenced by tillage and soil water content. Soil Biology \& Biochemistry 40, 967-977.

Reichstein, M., Beer, C., 2008. Soil respiration across scales: The importance of a model-data integration framework for data interpretation. J. Plant. Nutr. Soil Sci. 171, 344-354.

Rey, A., Petsikos, C., Jarvis, P.G., Grace, J., 2005. Effect of temperature and moisture on rates of carbon mineralization in a Mediterranean oak forest soil under controlled and field conditions. Europ. J. Soil Sci. 56, 589-599.

Schjonning, P., Thomsen, I.K., Moberg, J.P., de Jonge, H., Kristensen, K., Christensen, B.T., 1999. Turnover of organic matter in differently textured soils I. Physical characteristics of structurally disturbed and intact soils. Geoderma 89, 177-198.

Shirazi, M.A., Boersma, L., Hart, J.W., 1988. A unifying quantitative analysis of soil texture: Improvement of precision and extension of scale. Soil Sci. Soc. Am. J. 52, 181-190.

Simunek, J., Suarez, D.L., 1993. Modeling of carbon dioxide transport and production in soil: 1. Model development. Water Resources Research 29, 487-497.

Six, J., Paustian, K., Elliot, E.T., Combrink, C., 2000. Soil structure and soil organic matter: 1. Distribution of aggregate size classes and aggregate associated carbon. Soil Science Society of America Journal 64, 681-686.

Soil Science Glossary Terms Committee (2008). Glossary of Soil Science Terms 2008. Madison, WI: Soil Science Society of America. ISBN 978-0-89118-851-3.

Strong, D.T., De Wever, H., Merckx, R., Recous, S., 2004. Spatial location of carbon decomposition in the soil pore system. European Journal of Soil Science 55, 739-750.

Thomsen, I.K., Schonning, P., Jensen, B., Kristensen, K., Christensen, B.T., 1999. Turnover of organic matter in differently textured soils II. Microbial activity as influenced by soil water regimes. Geoderma 89, 199-218.

Unger, S., Maguas, C., Pereira, J.S., David, T.S., Werner, C., 2010. The influence of precipitation pulses on soil respiration - Assessing the "Birch effect" by stable carbon isotopes. Soil Biology \& Biochemistry 42, 1800-1810.

Van Genuchten, M.T., 1980. A closed form equation for predicting the hydraulic conductivity of unsaturated soils. Soil Science Society of America Journal 44, 892-898. 
Wang, X., Liu, L., Piao, S., Janssens, I.A., Tang, J., Liu, W., Chi, Y., Wang, J., Xu, S., 2014. Soil respiration under climatic warming: differential response of heterotrophic and autotrophic respiration. Global Change Biology. doi: 10.1111/gcb.12620.

Weihermüller, L., Huisman, J.A., Graf, A., Herbst, M., Sequaris, J.-M., 2009. Multistep outflow experiments for the simultaneous determination of soil physical and $\mathrm{CO}_{2}$ production parameters. Vadose Zone Journal 8, 772-782. 
Table 1

Soil classification and properties, $d_{g}$ represents the mean grain diameter according to Shirazi et al. (1988) and SOC is soil organic carbon

\begin{tabular}{|c|c|c|c|c|c|c|c|c|c|}
\hline soil/site & soil type & $\begin{array}{c}\text { depth } \\
\mathrm{cm}\end{array}$ & $\begin{array}{c}\text { clay } \\
\%\end{array}$ & $\begin{array}{l}\text { silt } \\
\%\end{array}$ & $\begin{array}{c}\text { sand } \\
\%\end{array}$ & $\begin{array}{c}d_{g} \\
\mu \mathrm{m}\end{array}$ & $\begin{array}{c}\text { SOC } \\
\text { g } 100 g^{-1}\end{array}$ & $\begin{array}{c}\text { bulk } \\
\text { density } \\
\mathrm{g} \mathrm{cm}^{-3}\end{array}$ & \multirow{2}{*}{$\begin{array}{l}\text { reference } \\
\text { Kasteel et al., }\end{array}$} \\
\hline LM & Orthic & & & & & & & & \\
\hline Merzenhausen & Luvisol & 35 & 18 & 79 & 3 & 19.3 & 1.04 & 1.356 & \multirow{4}{*}{$\begin{array}{l}\text { Herbst et al., } \\
2009\end{array}$} \\
\hline LS & Haplic & & & & & & & & \\
\hline Selhausen & Luvisol & 33 & 18 & 67 & 15 & 29.6 & 1.13 & 1.365 & \\
\hline SP & Fluvic & & & & & & & & \\
\hline Pulheim & Cambisol & 39 & 4 & 21 & 75 & 390.4 & 0.83 & 1.430 & \multirow{3}{*}{$\begin{array}{l}\text { - } \\
\text { Weihermüller } \\
\text { et al., } 2009\end{array}$} \\
\hline & Gleyic & & & & & & & & \\
\hline Kaldenkirchen & Cambisol & 30 & 2 & 8 & 90 & 681.2 & 0.84 & 1.455 & \\
\hline
\end{tabular}




\section{Table 2}

Soil hydraulic parameters of the sieved and the undisturbed samples; water content at saturation $\theta_{\mathrm{s}}$, residual water content $\theta_{\mathrm{r}}$, inverse air entry pressure $\alpha_{1}$, slope parameter $n_{l}$ and the weighting factor $\omega_{1}$ of the bi-modal approach (Eq. 2). Subscript 2 refers to the macropore system.

\begin{tabular}{lccccccc}
\hline soil & $\begin{array}{c}\theta_{\mathrm{s}} \\
\mathrm{cm}^{3} \mathrm{~cm}^{-3}\end{array}$ & $\begin{array}{c}\theta_{\mathrm{r}} \\
\mathrm{cm}^{3} \mathrm{~cm}^{-3}\end{array}$ & $\begin{array}{c}\alpha_{1} \\
\mathrm{~cm}^{-1}\end{array}$ & $\begin{array}{c}n_{1} \\
-\end{array}$ & $\begin{array}{c}\alpha_{2} \\
\mathrm{~cm}^{-1}\end{array}$ & $\begin{array}{c}n_{2} \\
-\end{array}$ & $\begin{array}{c}\omega_{1} \\
-\end{array}$ \\
\hline LM & 0.551 & 0 & 0.0393 & 1.29 & - & - & - \\
LS & 0.503 & 0 & 0.0086 & 1.27 & - & - & - \\
SP & 0.423 & 0.016 & 0.0899 & 1.37 & - & - & - \\
SK & 0.472 & 0.015 & 0.0271 & 1.77 & - & - & - \\
\hline \multicolumn{7}{c}{ sieved } \\
LM & 0.409 & 0 & 0.0081 & 1.28 & 0.094 & 4.53 & 0.85 \\
LS & 0.429 & 0 & 0.0019 & 1.42 & 0.192 & 2.69 & 0.75 \\
SP & 0.375 & 0 & 0.0441 & 1.34 & - & - & - \\
SK & 0.356 & 0 & 0.0293 & 1.29 & - & - & - \\
\hline
\end{tabular}


Table 3 Number of estimated parameters $p$, corrected Akaike information criterion $\mathrm{AIC}_{\mathrm{c}}$, coefficient of model efficiency ME and root mean square error RMSE of potential models.

\begin{tabular}{|c|c|c|c|c|c|}
\hline & \multicolumn{5}{|c|}{$\mu \mathrm{g} \mathrm{CO}{ }_{2} \min ^{-1} \mathrm{~g}$} \\
\hline & & & & sieved & \\
\hline $\mathrm{LM}$ & 3 & -72.5 & 0.97 & 0.00053 & \\
\hline LS & 3 & -73.5 & 0.89 & 0.00049 & gaussian type \\
\hline SP & 3 & -71.0 & 0.98 & 0.00060 & Eq. (6) \\
\hline SK & 3 & -69.9 & 0.88 & 0.00066 & \\
\hline LM & 2 & -83.2 & 0.97 & 0.00050 & \\
\hline LS & 2 & -83.5 & 0.89 & 0.00049 & square root \\
\hline SP & 2 & -84.3 & 0.99 & 0.00046 & Eq. (7) \\
\hline SK & 2 & -71.2 & 0.48 & 0.00136 & \\
\hline LM & 2 & -83.0 & 0.97 & 0.00051 & \\
\hline LS & 2 & -83.4 & 0.89 & 0.00049 & exponential \\
\hline SP & 2 & -82.1 & 0.98 & 0.00055 & Eq. (8) \\
\hline SK & 2 & -70.9 & 0.46 & 0.00140 & \\
\hline LM & 2 & -74.8 & 0.87 & 0.00101 & \\
\hline LS & 2 & -80.5 & 0.82 & 0.00063 & quadratic \\
\hline SP & 2 & -70.4 & 0.87 & 0.00145 & Eq. (5) \\
\hline SK & 2 & -69.4 & 0.31 & $\begin{array}{c}0.00158 \\
\text { undisturbed }\end{array}$ & \\
\hline LM & 1 & -79.6 & 0.95 & 0.00102 & \\
\hline LS & 1 & -84.8 & 0.91 & 0.00066 & linear \\
\hline SP & 1 & -65.4 & 0.62 & 0.00334 & Eq. (3) \\
\hline SK & 1 & -78.0 & 0.68 & 0.00117 & \\
\hline $\mathrm{LM}$ & 2 & -75.5 & 0.96 & 0.00095 & \\
\hline LS & 2 & -84.0 & 0.96 & 0.00047 & linear with intercept \\
\hline SP & 2 & -67.2 & 0.88 & 0.00190 & Eq. (4) \\
\hline SK & 2 & -84.3 & 0.95 & 0.00046 & \\
\hline $\mathrm{LM}$ & 2 & -80.1 & 0.98 & 0.00065 & \\
\hline LS & 2 & -87.7 & 0.98 & 0.00034 & quadratic \\
\hline $\mathrm{SP}$ & 2 & -62.2 & 0.72 & 0.00287 & Eq. (5) \\
\hline SK & 2 & -83.3 & 0.94 & 0.00049 & \\
\hline LM & 3 & -71.5 & 0.99 & 0.00058 & \\
\hline LS & 3 & -77.7 & 0.98 & 0.00035 & gaussian type \\
\hline SP & 3 & -71.9 & 0.99 & 0.00056 & Eq. (6) \\
\hline SK & 3 & -73.7 & 0.95 & 0.00048 & \\
\hline
\end{tabular}




\section{Table 4}

Final set of parameters (see Eqs. 5, 6, 9 and 10) and relative asymptotic standard errors

\begin{tabular}{|c|c|c|c|c|c|}
\hline \multirow[b]{3}{*}{ soil } & \multicolumn{5}{|c|}{ sieved } \\
\hline & & & & \multicolumn{2}{|c|}{ normalized } \\
\hline & $j$ & $k$ & $t_{r}$ & $k_{n}$ & $t_{r}$ \\
\hline \multirow[t]{2}{*}{ LM } & 0.0014 & 0.0083 & 0.463 & 0.855 & 0.463 \\
\hline & $\pm 52.8 \%$ & $\pm 13.9 \%$ & $\pm 23.2 \%$ & $\pm 6.8 \%$ & $\pm 8.3 \%$ \\
\hline \multirow[t]{2}{*}{ LS } & 0.0026 & 0.0060 & 0.377 & 0.699 & 0.377 \\
\hline & $\pm 56.3 \%$ & $\pm 20.6 \%$ & $\pm 39.4 \%$ & $\pm 15.5 \%$ & $\pm 12.7 \%$ \\
\hline \multirow[t]{2}{*}{ SP } & -0.0008 & 0.0129 & 0.414 & 1.063 & 0.414 \\
\hline & $\pm 106.6 \%$ & $\pm 9.5 \%$ & $\pm 14.0 \%$ & $\pm 5.1 \%$ & $\pm 7.3 \%$ \\
\hline \multirow[t]{5}{*}{ SK } & -0.0766 & 0.0880 & 0.089 & 7.680 & 0.089 \\
\hline & $\pm 208.3 \%$ & $\pm 181.1 \%$ & $\pm 30.2 \%$ & $\pm 150.6 \%$ & $\pm 24.6 \%$ \\
\hline & \multicolumn{5}{|c|}{ undisturbed } \\
\hline & & & \multicolumn{3}{|c|}{ normalized } \\
\hline & $d$ & $g$ & & $g_{n}$ & \\
\hline \multirow[t]{2}{*}{$\mathrm{LM}$} & 0.0042 & 0.0138 & & 0.769 & \\
\hline & $\pm 11.7 \%$ & $\pm 7.0 \%$ & & $\pm 3.0 \%$ & \\
\hline \multirow[t]{2}{*}{ LS } & 0.0044 & 0.0127 & & 0.743 & \\
\hline & $\pm 7.1 \%$ & $\pm 7.9 \%$ & & $\pm 1.6 \%$ & \\
\hline \multirow[t]{2}{*}{ SP } & 0.0092 & 0.0158 & & 0.632 & \\
\hline & $\pm 20.1 \%$ & $\pm 31.5 \%$ & & $\pm 9.9 \%$ & \\
\hline \multirow[t]{2}{*}{ SK } & 0.0044 & 0.0084 & & 0.653 & \\
\hline & $\pm 8.3 \%$ & $\pm 12.4 \%$ & & $\pm 3.4 \%$ & \\
\hline
\end{tabular}




\section{Table 5}

Pearson coefficient of correlation between parameters of the normalized models (Eqs. 9 and 10) and soil properties; mean grain size diameter $d_{g}$, organic carbon content SOC, bulk density $\rho_{\mathrm{b}}$, water content at saturation $\theta_{\mathrm{s}}$, inverse air entry pressure $\alpha_{1}$, slope parameter $n_{l}$

\begin{tabular}{lcccc}
\hline & \multicolumn{2}{c}{ sieved } & & undisturbed \\
\cline { 2 - 3 } & $k_{n}$ & $t_{r}$ & $g_{n}$ \\
clay & -0.67 & 0.64 & & $0.97^{* * *}$ \\
silt & -0.71 & 0.71 & & $0.96^{* * *}$ \\
sand & 0.71 & -0.70 & $-0.96^{* * *}$ \\
$d_{g}$ & 0.86 & -0.83 & -0.86 \\
SOC & -0.57 & 0.49 & $0.91^{*}$ \\
$\rho_{\mathrm{b}}$ & 0.72 & -0.55 & $-0.94^{*}$ \\
$\theta_{\mathrm{s}}$ & -0.22 & 0.28 & 0.85 \\
$\alpha_{1}$ & -0.23 & 0.32 & $-0.94^{*}$ \\
$n_{l}$ & $0.99 * * *$ & $-0.96^{* *}$ & 0.13 \\
\hline
\end{tabular}

significant at $p<* 0.05 * * 0.025 * * * 0.01$ 


\section{FIGURE CAPTIONS}

Figure 1. Soil water retention curves of the undisturbed samples (a) and the sieved samples (b)

Fig 2. Mean and standard deviation of heterotrophic respiration against effective saturation $\Theta_{\mathrm{e}}$ of sieved soils. Lines represent the model fit according to Eq. 6 .

Fig 3. Mean and standard deviation of heterotrophic respiration against effective saturation $\Theta_{\mathrm{e}}$ of undisturbed soils. Lines represent a quadratic model fit (Eq. 5).

Fig 4. Mean and standard deviation of normalized heterotrophic respiration $R_{n}$ against effective saturation $\Theta_{\mathrm{e}}$ of sieved soils. Lines represent the model fit according to Eq. 10. The model fit to the data of Lee et al. (2004) is represented by a solid black line.

Fig 5. Mean and standard deviation of normalized heterotrophic respiration $R_{n}$ against effective saturation $\Theta_{\mathrm{e}}$ of undisturbed soils. Lines represent the model fit according to Eq. 9. Literature data was taken from Peterson et al. (2008) and Borken et al. (2003), model fits are represented by soild black and dashed black line, respectively.

Fig. 6 Comparison of the normalized heterotrophic respiration $R_{n}$ against effective saturation $\Theta_{\mathrm{e}}$ of all sieved and all undisturbed soils. Shaded area represents the asymptotic standard error of the fitted black line. 
Fig. 1
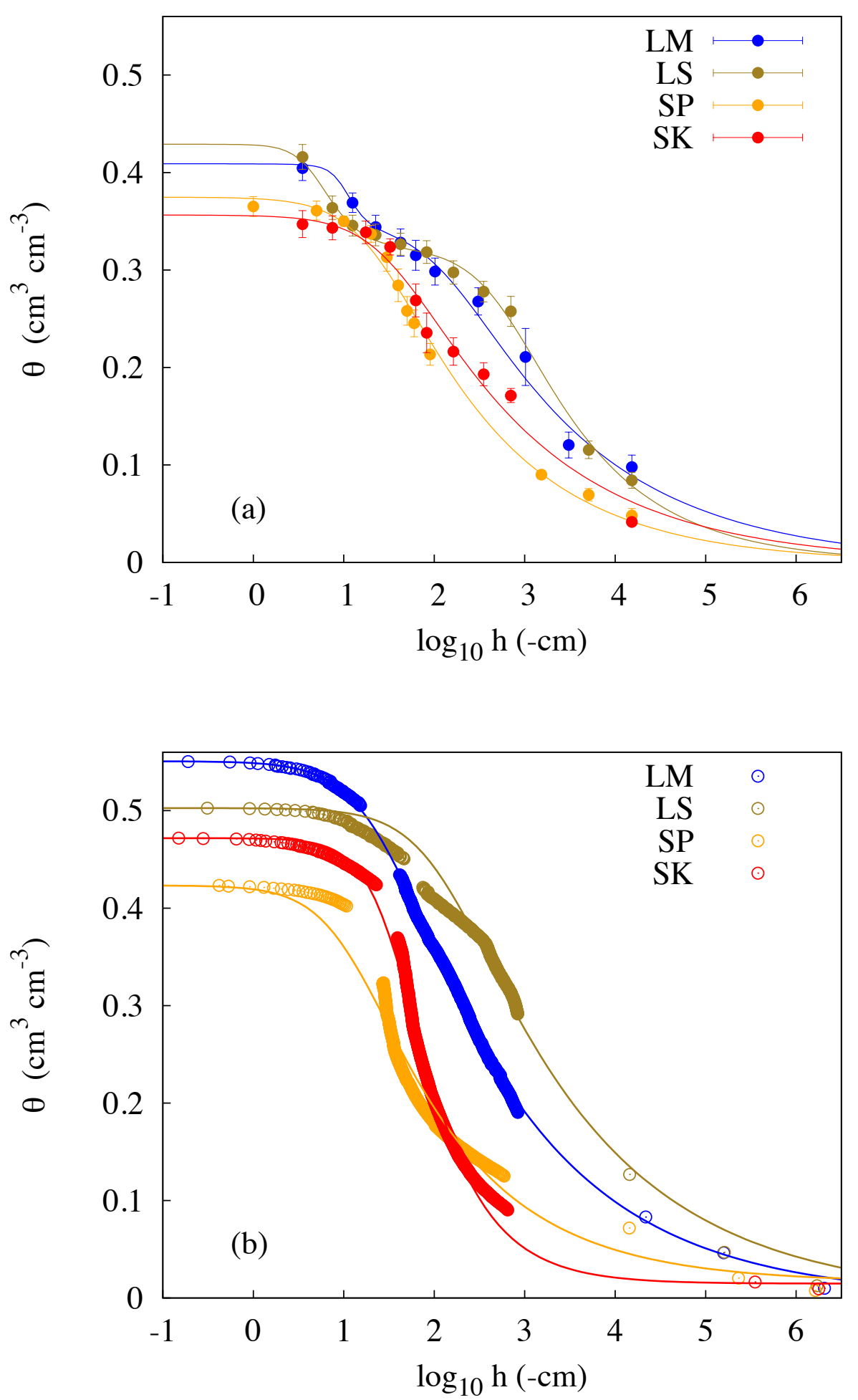
Fig. 2

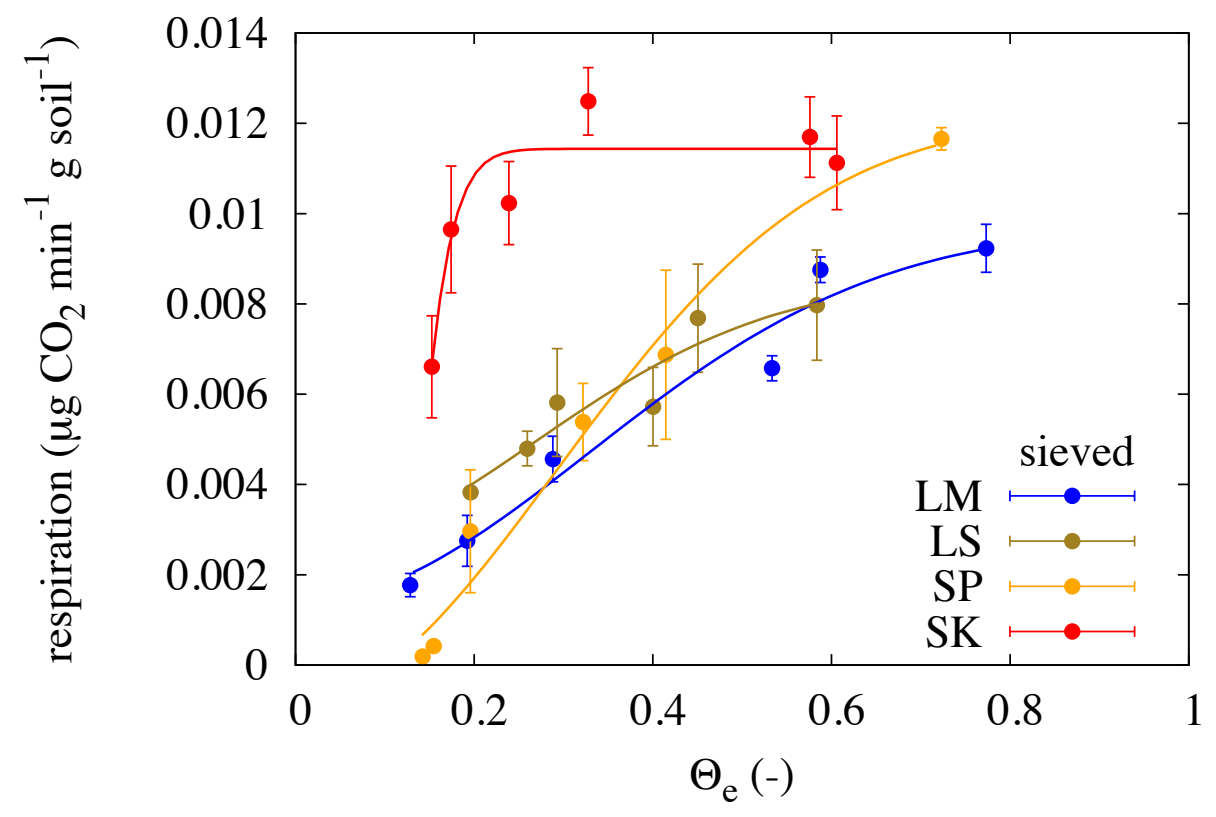


Fig. 3

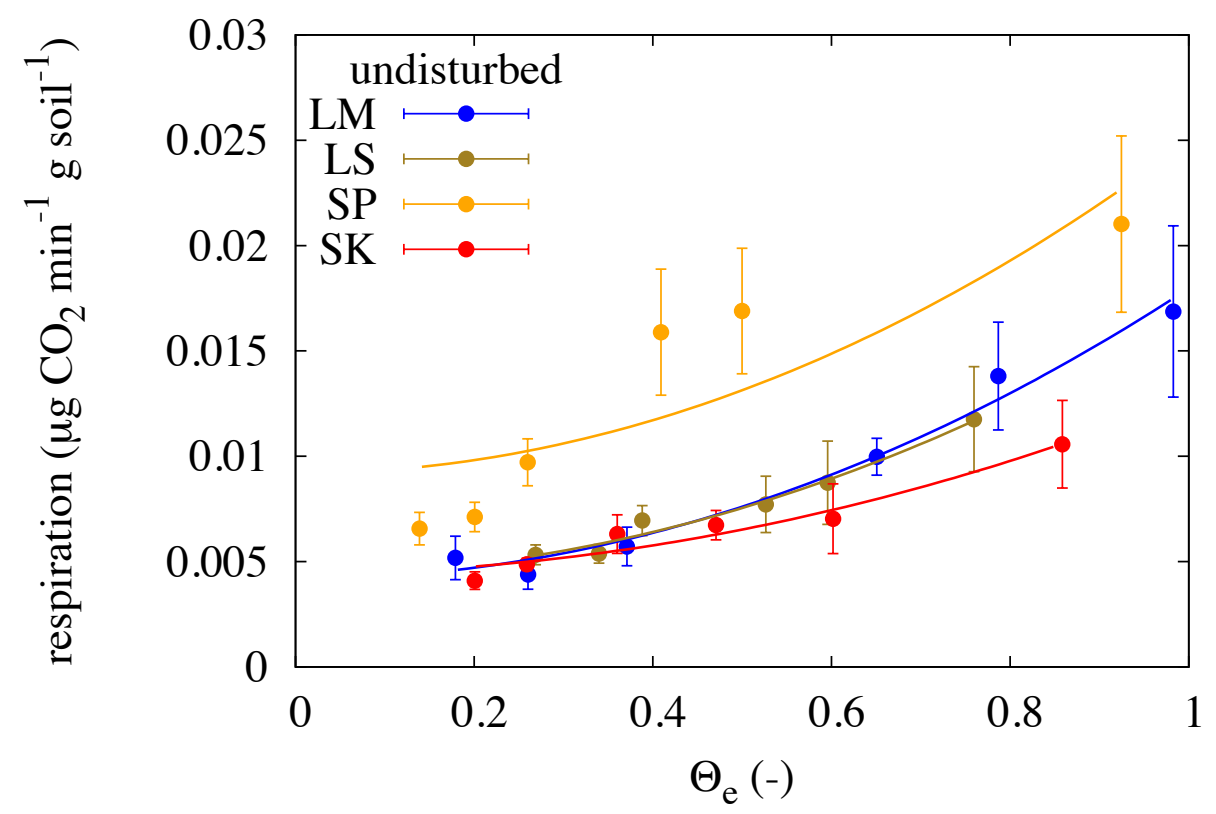


Fig. 4

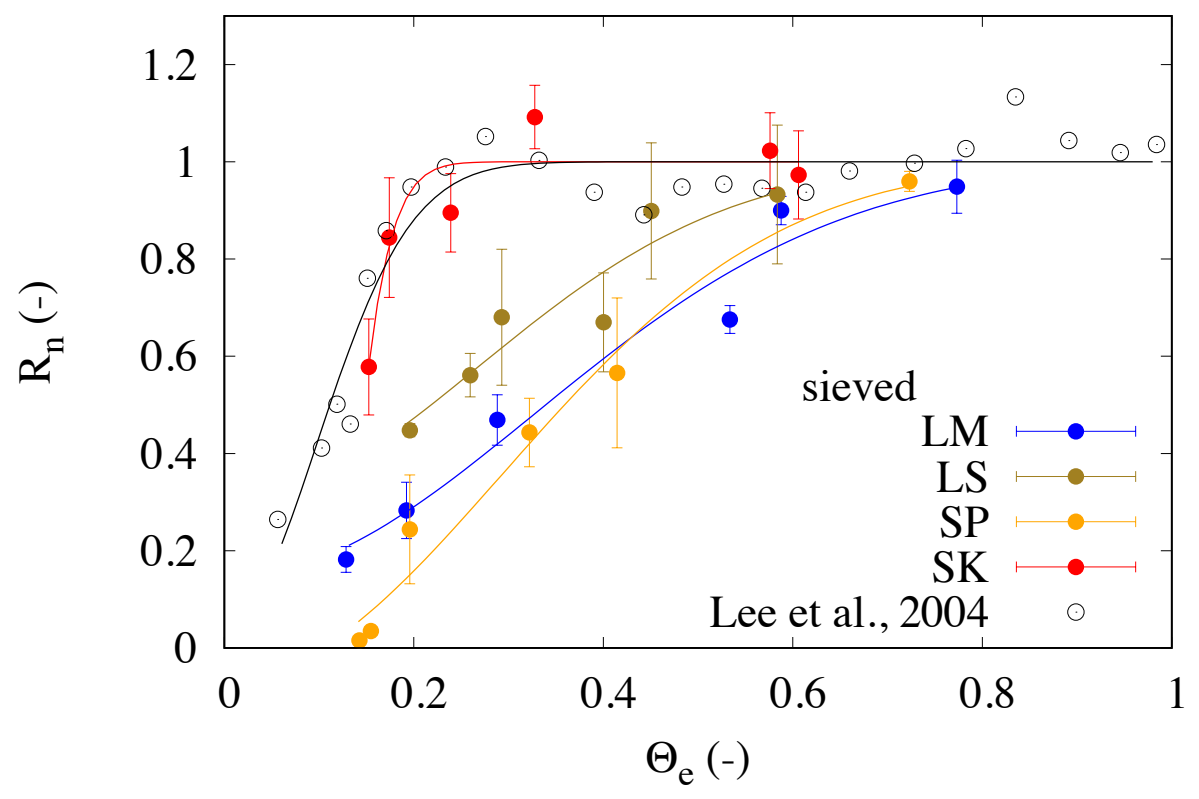


Fig. 5

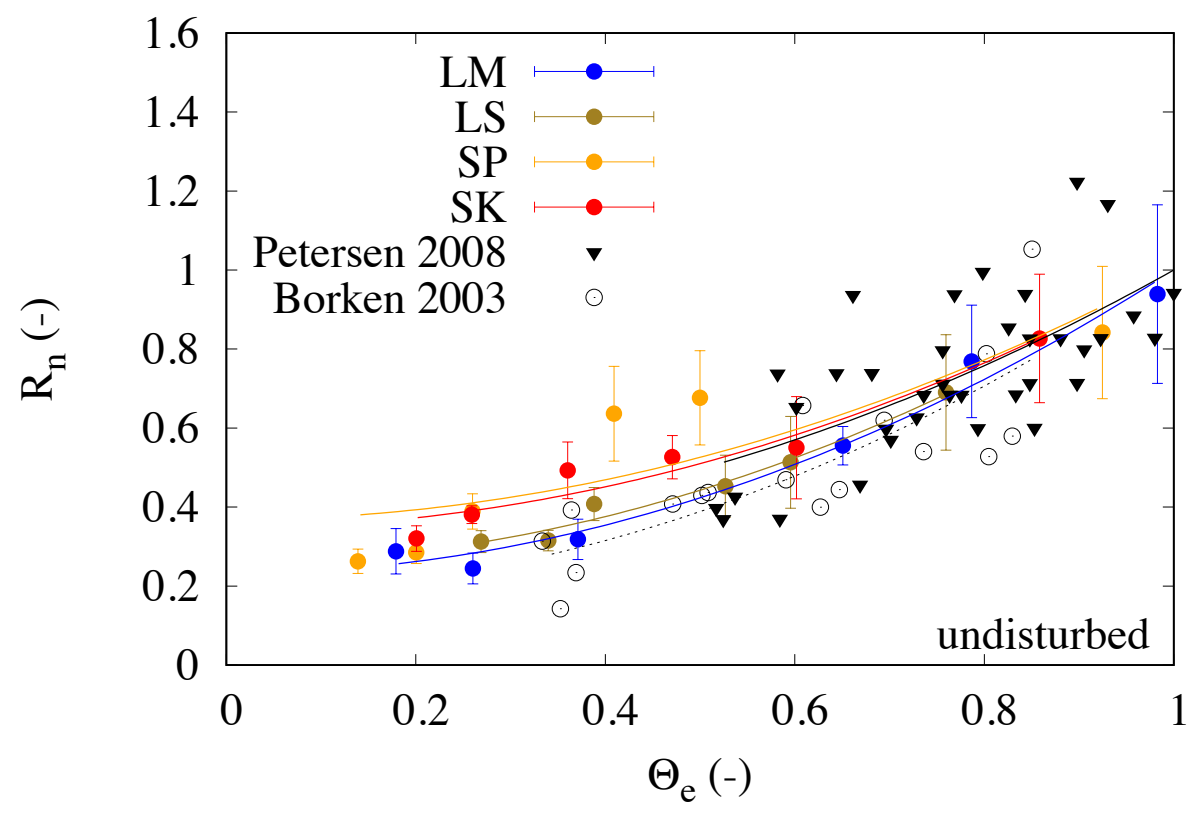


Fig. 6

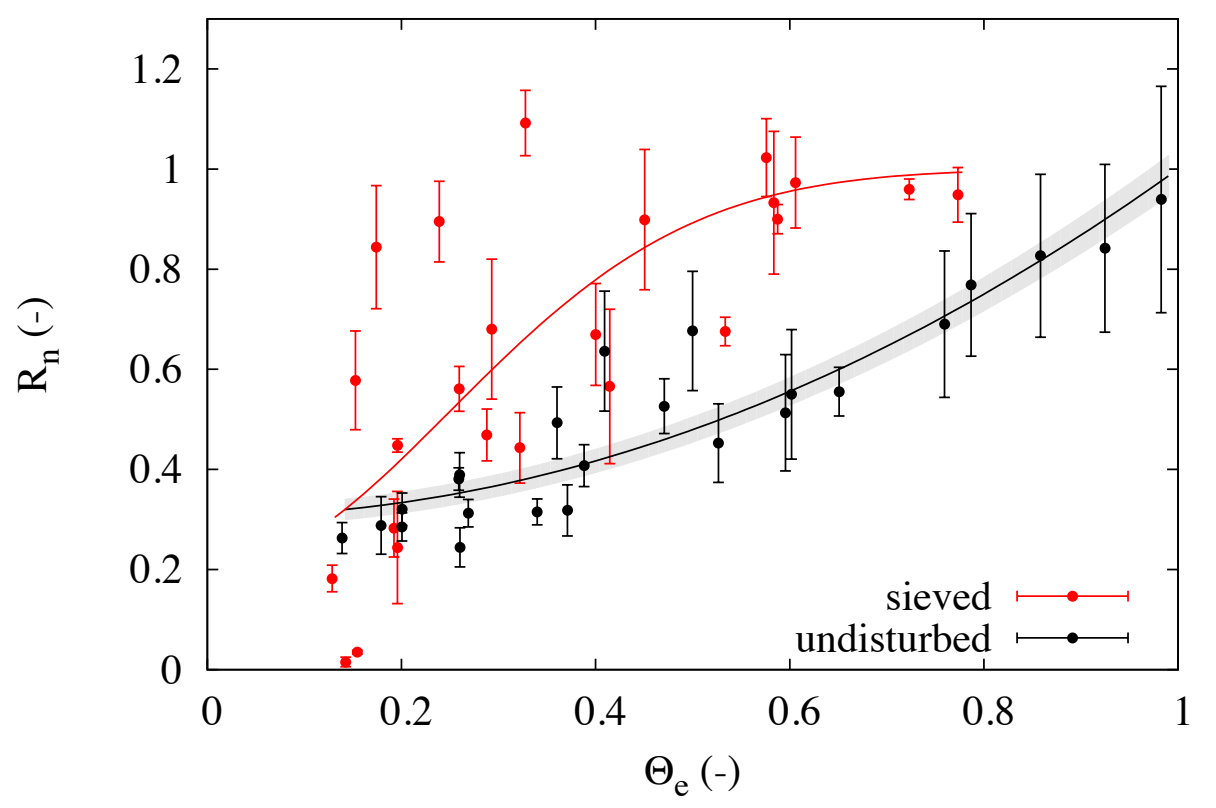




\section{Supplement}

Extraction of the respiration rate from the respirometer raw data

In order to determine the basal respiration rate at the beginning of the incubation the raw data was processed as follows. During the incubation period the measured $\mathrm{CO}_{2}$ fluxes were not constant for 4 reasons:

(i) micro-fluctuations in room temperature

(ii) decrease of soil water content over the incubation period due to the permanent air stream

(iii) limited $\mathrm{CO}_{2}$ diffusion in soil air caused increasing $\mathrm{CO}_{2}$ emissions during the initial period of incubation before equilibration of pore $\mathrm{CO}_{2}$ concentration with $\mathrm{CO}_{2}$ concentration in ambient air, particularly observed for high water contents

(iv) equilibration of the $\mathrm{CO}_{2}$ dissolved in the pore water according to ambient air pressure; very low water contents were imposed using high positive pressures (up to $15848 \mathrm{~cm} \approx 16$ bar) in the pressure cells, which caused high liquid phase $\mathrm{CO}_{2}$ concentrations compared to ambient concentrations; high water contents were imposed using a sandbed with negative pressures, which in turn caused low liquid phase $\mathrm{CO}_{2}$ concentrations compared to concentrations prevailing under ambient atmospheric conditions

To account for all these effects the following equation was fitted to the incubation data:

$f(t)=a+b * e^{(-k * t)}+c * t+h * \sin (i+j * t)$

where $a$ is the intercept, $b$ scales the exponential part defined by the rate $k, c$ scales the linear part, $h$ defines the amplitude of the sine wave and $j$ defines the shift of the sine wave in time $t$. The exponential part accounts for effects of $\mathrm{CO}_{2}$ concentration equilibration and diffusion, the linear part accounts for the effect of a decrease in water content over time and the sine wave accounts for micro-fluctuations in room temperature. Removing the exponential part $\left(=b * e^{-}\right.$ $\left.k^{*}\right)$ ) from Eq. 12 allowed to compute the basal respiration at the beginning of the incubation at $\mathrm{t}=0$ with all the above-mentioned effects removed. 
The two example figures show the raw data and the respective model fits according to Eq. 12 . Five replicates each of undisturbed Merzenhausen soil (LM) were incubated after adjustment to a pressure head of $-300 \mathrm{~cm}$ (Figure a) and $-15848 \mathrm{~cm}$ (Figure b). The dashed lines represent the models with the exponential part removed and the $y$-intercept (at time $=0$ ) of those five functions was averaged for the consecutive analyses.
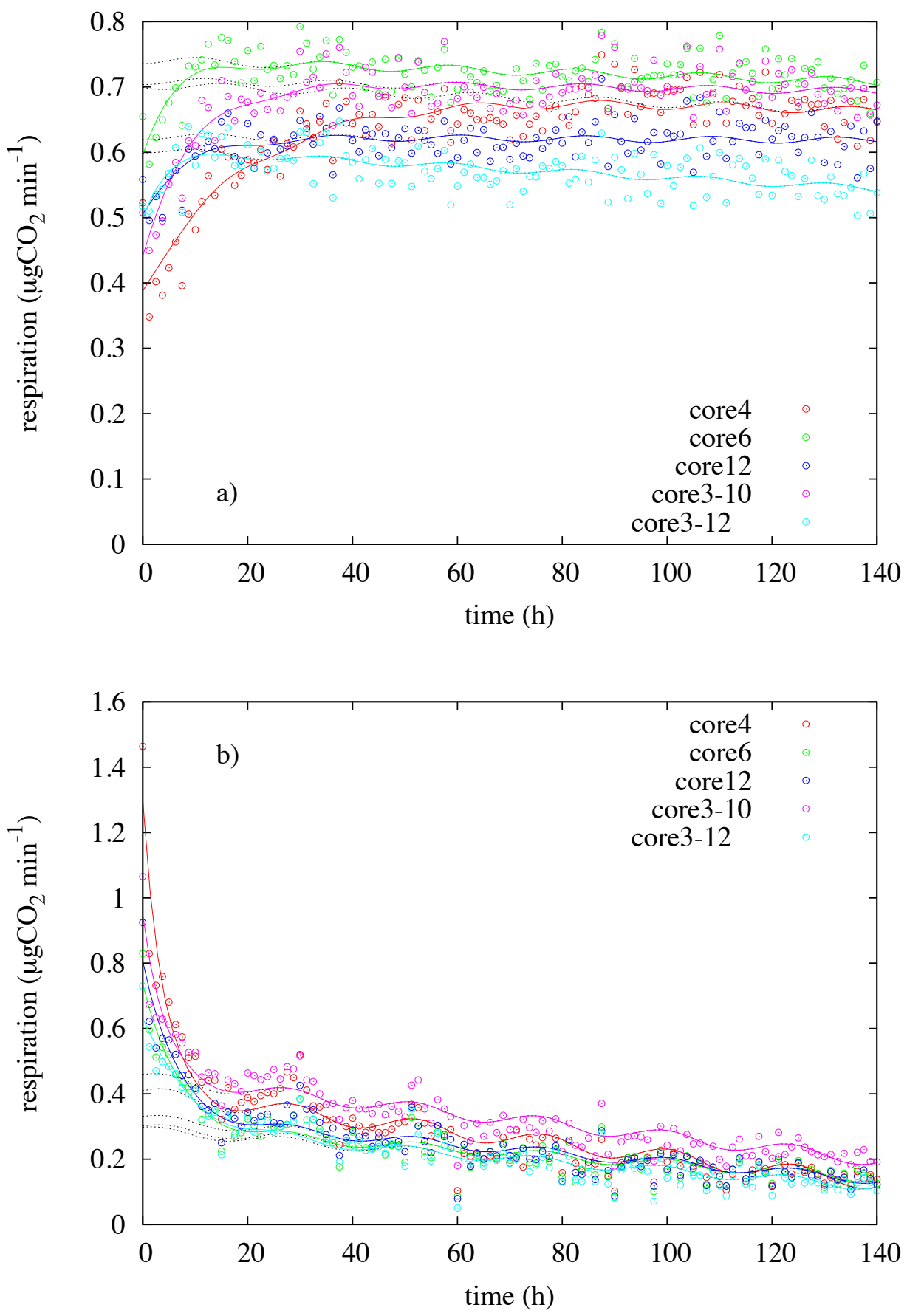